\title{
Colorectal Screening Program in Northern Portugal: First Findings
}

\section{Programa de Rastreio de Cancro Colo-Rectal no Norte de Portugal: Primeiros Resultados}

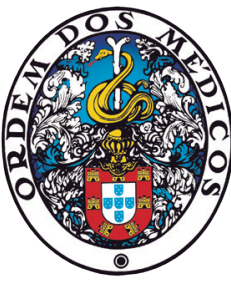

\author{
Hugo MONTEIRO ${ }^{1}$, Fernando TAVARES ${ }^{1}$, João REIS ${ }^{1}$, Gustavo FERREIRA², M. José CAMPOS ${ }^{3}$, Sérgio COSTA $^{1}$, \\ Laura CARVALHO ${ }^{4}$, João CARVALHO ${ }^{5}$, Isabel PEDROTO ${ }^{6}$, José SOARES ${ }^{7}$, Rui HENRIQUE ${ }^{8}$, Maria José BENTO ${ }^{9,10}$, \\ Cesare HASSAN ${ }^{11}$, Mário DINIS-RIBEIRO ${ }^{12}$ \\ Acta Med Port 2022 Mar;35(3):164-169 - https://doi.org/10.20344/amp.15904
}

\section{ABSTRACT}

Introduction: In Portugal, a colorectal cancer screening program based on faecal immunochemical test followed by colonoscopy was shown to be cost-effective for individuals between 50 and 74 years old. We report the first findings of the implementation of a population-based program In Northern Portugal.

Material and Methods: In the pilot phase, eligible subjects were allocated either to a direct mailing invitation or to primary care centers. In the first year of program implementation, we assessed the uptake rate, the faecal immunochemical test -positivity rate, the diagnostic yield of advanced neoplasia, and the quality parameters for post-faecal immunochemical test + colonoscopy.

Results: We invited 100501 eligible subjects (49\% male with a median age of 55 years). Of these, 5228 participated in the pilot phase and 95273 participated in the first year of the program. In the first year of the program, the adherence was $29 \%$, with a positivity rate of $5 \%$ and a $60 \%$ compliance to colonoscopy. The faecal immunochemical test-detection rate of advanced neoplasia was $0.35 / 1000$ subjects, and the positive predictive value at post- faecal immunochemical test + colonoscopy was $44 \%$ and $2 \%$ for advanced adenoma and invasive cancer, respectively. No major adverse events were reported after colonoscopy.

Conclusion: A centralized invitation system based on direct mailing was feasible and both colonoscopy quality and diagnostic yield were adequate antecipating the success of the programme.

Keywords: Colonoscopy; Colorectal Neoplasms; Early Detection of Cancer; Mass Screening; Occult Blood; Portugal

\section{RESUMO}

Introdução: Em Portugal, foi demonstrado que o rastreio do cancro colo-rectal, baseado no teste imunoquímico fecal seguido de colonoscopia, seria custo-efetivo para indivíduos entre os 50 e 74 anos. Neste artigo reportamos os primeiros resultados da implementação do programa de base populacional na região Norte de Portugal.

Material e Métodos: Na fase piloto, os sujeitos elegíveis foram alocados a dois métodos, por convite através do correio ou por meio de entrega direta nos centros de saúde. No primeiro ano de implementação do programa avaliámos a taxa de adesão, a taxa de positividade de teste imunoquímico fecal, o rendimento diagnóstico de neoplasia avançada e os parâmetros de qualidade da colonoscopia pós- teste imunoquímico fecal positivo.

Resultados: Foram convidados 100501 indivíduos elegíveis (49\% do sexo masculino com idade mediana de 55 anos). Destes, 5228 participaram na fase piloto e 95273 participaram no primeiro ano do programa. No primeiro ano do programa, a adesão foi de $29 \%$, com taxa de positividade de $5 \%$ e adesão de $60 \%$ às colonoscopias. A taxa de deteção de teste imunoquímico fecal de neoplasia avançada foi de $0,35 / 1000$ indivíduos, e o valor preditivo positivo na colonoscopia pós-teste imunoquímico fecal positivo foi de $44 \%$ e $2 \%$ para adenoma avançado e cancro invasivo, respetivamente. Não foi relatado nenhum evento adverso após colonoscopia.

Conclusão: Um sistema de convite centralizado foi viável, a qualidade das colonoscopias realizadas e o rendimento diagnóstico adequados antecipando o sucesso do programa.

Palavras-chave: Colonoscopia; Detecção Precoce de Cancro; Neoplasias Colorrectais; Portugal; Programas de Rastreio; Sangue Oculto

\section{INTRODUCTION}

Colorectal cancer $(\mathrm{CRC})$ is one of the most common cancers worldwide, accounting for one out of 10 cancer cases and deaths in the world. ${ }^{1}$ In Portugal, approximately 30 new CRC cases are diagnosed every day, representing

the most common type of cancer and the main oncological cause of premature death in individuals between 50 and 74 years old. ${ }^{2,3}$ Moreover, survival of CRC is as low as $58 \%$ at five years. ${ }^{4}$

1. Departamento de Estudos e Planeamento. Administração Regional de Saúde do Norte. Porto. Portugal.

2. Agrupamento de Centros de Saúde de Maia e Valongo. Maia. Portugal.

3. Agrupamento de Centros de Saúde de Póvoa do Varzim-Vila do Conde. Vila do Conde. Portugal.

4. Departamento de Gastroenterologia. Hospital de Vila Real. Vila Real. Portugal.

5. Departamento de Gastroenterologia. Centro Hospitalar de Gaia/Espinho. Espinho. Portugal.

6. Departamento de Gastroenterologia. Centro Hospitalar e Universitário do Porto. Porto. Portugal.

7. Departamento de Gastroenterologia. Hospital Pedro Hispano. Matosinhos. Portugal.

8. Departamento de Patologia. Instituto Português de Oncologia do Porto. Porto. Portugal.

9. North Region Cancer Registry (RORENO). Instituto Português de Oncologia do Porto. Porto. Portugal.

10. Departamento de Epidemiologia. Instituto Português de Oncologia do Porto. Porto. Portugal.

11. Endoscopy Unit. Nuovo Regina Margherita Hospital. Rome. Italy.

12. Departamento de Gastroenterologia. Instituto Português de Oncologia do Porto. Porto. Portugal.

$\triangle$ Autor correspondente: Mário Dinis-Ribeiro. mario.ribeiro@ipoporto.min-saude.pt

Recebido: 06 de fevereiro de 2021 - Aceite: 29 de abril de 2021 - First published: 20 de julho de 2021 - Online issue published: 02 de março de 2022 Copyright $\odot$ Ordem dos Médicos 2022 
Colorectal Cancer Screening should be a populationbased organized screening program aimed at covering all eligible individuals, regardless of gender, from the 50 - 74 years of age cohort. ${ }^{5-7}$ Two main strategies, namely Fecal Immunochemical test (FIT) with post-FIT+ colonoscopy and primary screening colonoscopy, are currently used in different countries. In particular, FIT has shown superior accuracy and acceptability when compared with previous guaiac-based faecal tests. ${ }^{8,9}$ In Portugal, a Markov cost-utility analysis comparing biennial FIT versus primary screening colonoscopy every 10 years showed the higher cost-effective profile of the former option. ${ }^{10}$

The Northern Portugal Regional Health Administration (ARSN) recommended a systematic approach while implementing a $\mathrm{CRC}$ screening program. ${ }^{11} \mathrm{~A}$ team was created to coordinate the screening program, centralized at ARSN, and targeting the 1100000 inhabitants aged between 50 and 74 years old. In December 2016, ARSN launched a pilot-program aimed at to comparing two different methodologies for invitation, i.e. centralized invitation based on direct mailing versus capillary invitation through organized visits to Primary Care Centers (PCC). Early in 2018, the program was expanded to the regional level.

Our aim is to report the results of the pilot program and of the first year of regional implementation concerning adherence and detection rate of advanced neoplasia, as well as to assess the quality of post-FIT+ colonoscopy and surveillance.

\section{MATERIAL AND METHODS \\ Coordination team and organizational strategy}

A coordination team of healthcare professionals was created to implement a CRC screening program. This team concentrated all executive decisions and was responsible for the monitoring and evaluation of the program. Briefly, a centralized information system [System for Monitoring and Evaluation of Health Programs, (SiiMA)] managed all the relevant outcomes, including adherence rate to FIT and post-FIT+ colonoscopy invitations, diagnostic yield for advanced neoplasia, and quality assessment. SiiMA was also linked to the national health databases for invitation of the population, to PCC, and to electronic health records through the endoscopic units. All FIT were performed in the same laboratory with a cut-off of $100 \mathrm{ng} / \mathrm{ml}$ (equivalent to 20 u/gr), ${ }^{12}$ (OC-Auto Sampling 3 Eiken Chemical Co., Ltd.). Finally, all individuals eligible for screening were included in this screening and both FIT and colonoscopy were offered free of charge.

\section{Pilot program}

In December 2016, the pilot-program was aimed at testing the uptake rate of two different invitation strategies for FIT (Fig. 1). For that, each method was applied in two different areas:

- Method A with a direct invitation and FIT test sent to citizen by regular mail. Individuals were first presented with an awareness letter, inviting, and informing about the im- portance of screening and what would happen next. All individuals could self-exclude themselves from the screening program by calling or emailing the coordination team. A few days later, a second letter was sent with the FIT, explaining how to do the test and where to deliver it. A third letter was sent to promote delivery of the kit to those who had not yet delivered the FIT at their PCC. In this case, the endoscopic unit was $30 \mathrm{~km}$ away from the unit.

- Method B where the relationship between the individuals and their health team was explored. Briefly, Portuguese PCC are organized as 'health teams' where all healthcare professionals align their actions in order to treat every patient within a certain 'list' of patients. In this case, after the invitation letter, the FIT was delivered by a nurse. Finally, for those accepting, they would deliver the FIT at the physical space of the primary care centers (a specific box was designed for this pilot and placed at the entrance of the primary care centers) and were transported to a regional laboratory to be analyzed. In this case, the endoscopic unit was close to the inhabitants' residence.

Each method ( $A$ and $B$ ) was tested in specific areas and colonoscopies performed in two different centers (colonoscopy center 1 and 2, respectively). Both centers were public hospitals and also provided the histopathological assessment and the post-colonoscopy and diagnosis care if needed (endoscopic and/or surgery).

The inclusion criteria considered all individuals between 50 and 74 years of age, a residence registry with a match to a local primary care center inside the Northern Regional Health Administration (ARSN) catchment area, no previous family history of gastrointestinal diseases, no previous personal history of gastrointestinal diseases (identified through a search in the ARSN patient records using International Classification of Primary Care two (ICPC-2) codes) and no previous colonoscopy done in the last 10 years prior to the pilot-screening project (identified through a search in the national database).

The Portuguese National Health Service (SNS) has a centralized information system, and most citizens have an electronic health record run by the Ministry of Health. Also, most colonoscopies are paid by the NHS and there is, consequently, a registry of when the individuals had a colonoscopy.

The two colonoscopy centers used the digital platform for relevant clinical data registry. Information about colon or/ and rectum lesions were introduced by the gastroenterologist responsible for the endoscopic procedure (morphology and other histopathological data included).

\section{First year of FIT program at regional level}

In 2018, the program was expanded, corresponding to an estimated number of 250000 eligible patients to consider for invitation in the first year. In order to find the eligible patients, we performed a linkage process with the electronic health records of individuals, according to certain inclusion criteria, and close to 1100000 individuals were selected. Due to estimated operational challenges, the population 


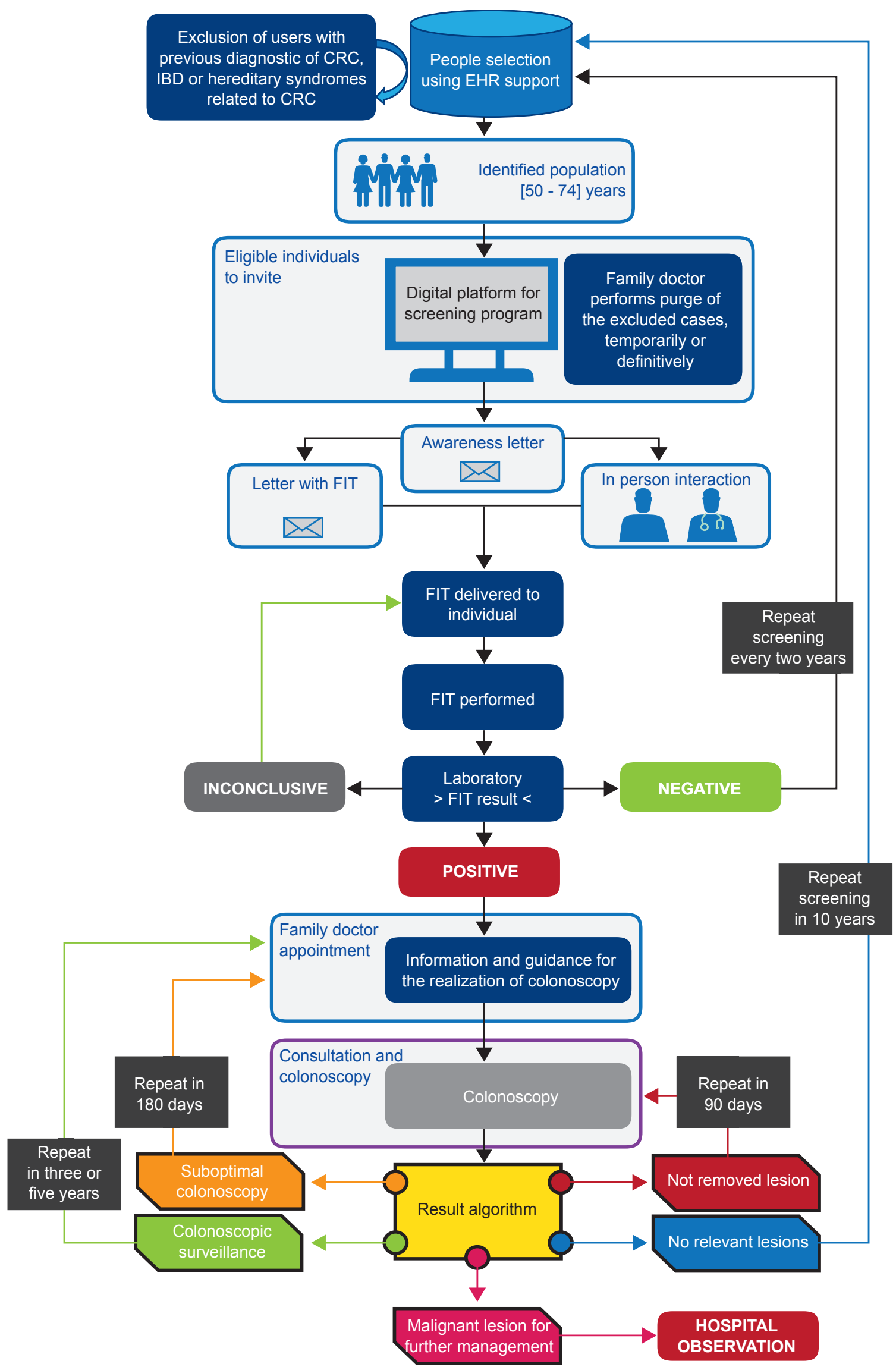

Figure 1 - Algorithm for the pilot study. After assessment the invitation by letter was decided. 
was divided in half for a two-year period of screening. After that period, all individuals were estimated to have been invited to the program and had the chance to participate. Therefore, a cycle would end, and a new cycle of selection would start. The workflow was kept according to the pilot program and opportunities for improvement were considered during the regional implementation. The coordination team decided that two mail letters should be sent, the first to invite for screening and a second one delivering the FIT test, including instructions on how to proceed. All FITs were taken to a central regional laboratory (ARSN, Regional Laboratory of Public Health) where all analysis was centered, and results published in the same digital platform. Results were automatically available to the Primary Care physicians of the individuals participating. Moreover, the closest public hospitals to the inhabitants' residence were used.

The main outcomes of FIT and post-FIT+ colonoscopy were collected, including various relevant operational variables (like refusal for colonoscopy orientation - positive cases, time values for laboratory reception and publication of results and time values for different appointment phases before and post hospital referral). In this paper we present the results of data from individuals that were invited up to June 2019 - meaning that only individuals below 70 years of age were selected. The exclusion criteria for invitation would be previous endoscopic procedures (colonoscopy in the past 10 years or sigmoidoscopy in the past five years) or surveillance due to familiar syndromes or inflammatory bowel disease (IBD).

Analysis was based on databases without any identification of specific individual data thus not requiring specific ethics committee approval.

\section{Statistical analysis}

Statistical analysis involved simple descriptive results regarding general traits of the individuals invited to participate and their results in key moments of the screening workflow. The results presented here focus on key metrics relevant for the screening project: participation rates, positive FIT rates, primary care consultation and management of positive cases, Hospital center response to referrals, adenoma detection rates after colonoscopy and neoplasm detection rates. ${ }^{13}$ The chi-square test was performed to compare different main variables related to the screening process in relation to method A and B ( $p$-value $<0.05)$ - rejecting the null-hypothesis suggests there is a difference between groups. We also performed a simple trend analysis to compare different key operational processes, between key moments of the screening program. The positive predictive value (PPV) determined for this study provided the probability that subjects with a positive screening test truly have the disease or certain stages of disease once detected. In practice, PPV is a key performance indicator for screening programs, in particular the FIT test use, because sensitivity and specificity cannot be derived without every patient going through a colonoscopy. Thus, a high PPV allows to infer high capacity of the screening test to detect positive cases.

\section{RESULTS}

\section{Pilot study}

Eligible individuals for screening were selected from two lists allocated to two primary care center groups. After linkage of the data referring to exclusion criteria with the electronic health records of individuals in the lists, a total of 5287 individuals were selected and divided according to the above groups. Method B presented higher adherence rates to FIT invitation ( $45 \%$ vs $37 \%, p<0.010)$ and post-FIT+ colonoscopy ( $66 \%$ vs $40 \%, p<0.010$; see Table 1$)$. However, the costs were significantly higher namely if adherence would be above $50 \%$. Both units provided high-quality key performance measures for colonoscopies.

\section{First year}

Eligible individuals for screening were selected from lists allocated to PCC groups and 95573 individuals were invited by mail to participate in the screening program - see Table 2. In terms of population demographics, this first year covered $85 \%$ of individuals of the 50 - 59 years of age range ( $15 \%$ from 60 to 69 years of age) and $51 \%$ were female. There were no noticeable age differences regarding adherence and diagnostic accuracy.

The main cause for exclusion (over $70 \%$ ) was the performance of a colonoscopy in the past 10 years or sigmoidoscopy in the past five years. A total of 27779 tests were

Table 1 - Overall results and per centers/methods the pilot phase

\begin{tabular}{|c|c|c|c|c|}
\hline & \multirow[t]{2}{*}{ Overall pilot } & \multicolumn{3}{|c|}{ Centers / Methods } \\
\hline & & Method A & Method B & $p$-value \\
\hline Invitees [n (\%)] & 5228 & 2640 & 2588 & \\
\hline Adherence to FIT [n (\%)] & $2143(41.0)$ & $970(37.0)$ & $1173(45.0)$ & $<0.001$ \\
\hline Positivity rate [n (\%)] & $127(5.9)$ & $47(4.8)$ & $80(6.8)$ & 0.002 \\
\hline Colonoscopies [n (\%)] & $72(57.0)$ & $19(40.0)$ & $53(66.0)$ & $<0.001$ \\
\hline ADR [n (\%)] & $62(86.0)$ & $12(63.0)$ & $40(75.0)$ & 0.256 \\
\hline Advanced phenotype rate* $[\mathrm{n}(\%)]$ & $35(49.0)$ & $10(52.0)$ & $25(47.0)$ & 0.606 \\
\hline Carcinoma** [n (\%)] & $2(2.0)$ & $1(5.0)$ & $1(2.0)$ & \\
\hline
\end{tabular}

ADR: adenoma detection rate; $n$ : absolute value; \%: proportion in relation to total value in context

* Advanced phenotype -3 or more adenomas or one adenoma $>10 \mathrm{~mm}$ or villous component or high-grade dysplasia

** Advanced carcinoma 
Table 2 - First year results: main results

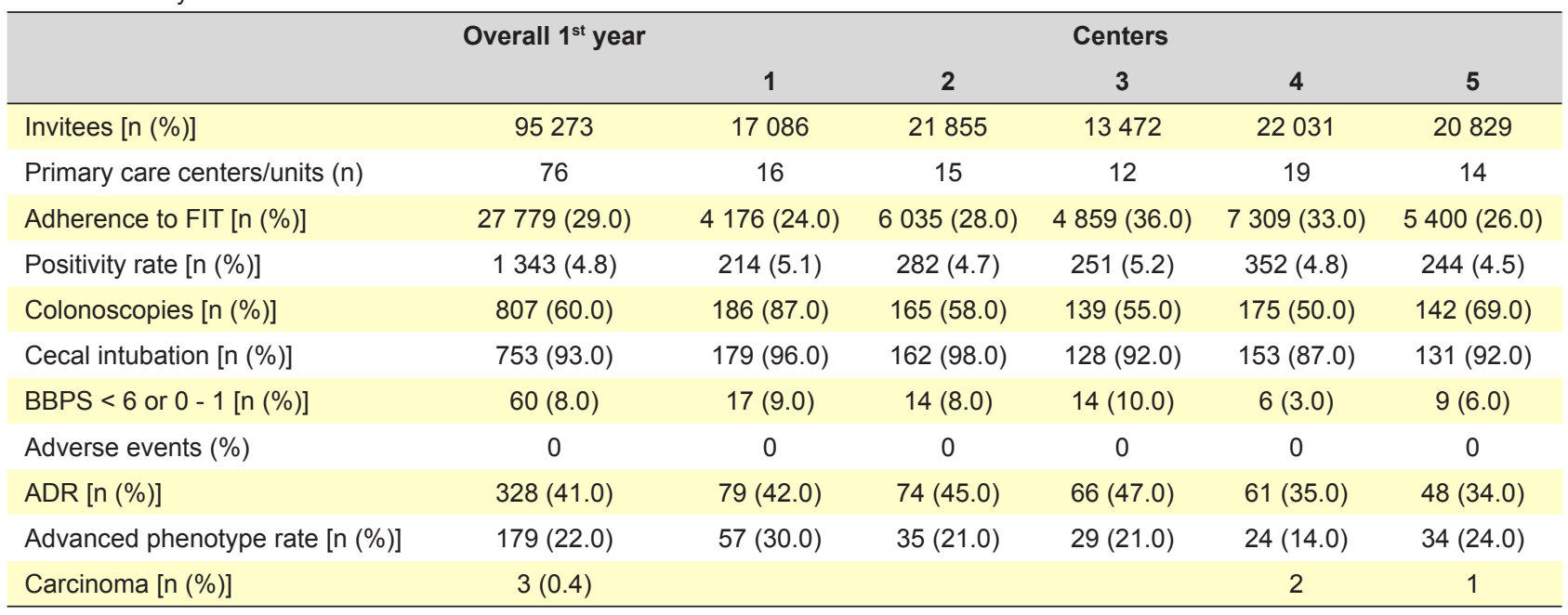

performed resulting in a FIT participation rate of $29 \%$. The average turnaround time of a test was 53 days (29 SD). Less than $1 \%(0.6 \%)$ of laboratory tests had inconclusive results, and in this case a new FIT test was sent to the individual.

Simple trend analysis by trimester of the median days between FIT result and a family doctor appointment show a trend of smaller and smaller periods of time. As the programme advanced, there was a clear effort in improving time-to-appointment, between result and primary care consultation. A summary is presented as text 21 days ( $1^{\text {st }}$ trimester $), 46$ days ( $2^{\text {nd }}$ semester $), 32\left(3^{\text {rd }}\right), 19\left(4^{\text {th }}\right), 22\left(5^{\text {th }}\right)$ and $18\left(6^{\text {th }}\right)$.

There were 1343 positive tests $(4.8 \%)$, with a compliance of $60 \%(807 / 1343)$ to post-FIT+ colonoscopy. There were no adverse events across all centers in the period of observation. Also, cecal intubation and bowel preparation was above standard (e.g., adequate). Among those that underwent colonoscopy, the positive predictive value (PPV) for any adenoma was $80 \%$, whereas the PPV for advanced adenoma and invasive cancer was $44 \%$ and $2 \%$, respectively. The overall detection of advanced adenoma and invasive cancer was 179/95 273 (1.9 per 1000) and 10/95 273 (0.1 per 1000), respectively.

\section{DISCUSSION}

According to our study, a strategy to direct invitation to the target population is effective when inviting eligible subjects to FIT screening. However, a low uptake for FIT and a suboptimal compliance to post-FIT colonoscopy were recorded, suggesting the need for additional adjustments.

In the pilot study, the superiority of a Primary Care physician-filtered invitation over direct invitation was different from other countries. In Italy, a randomized trial on the same interventions led to opposite outcomes - Table 3. This may be due to the differences in interest or awareness of PCP for such activity, especially when considering the substantial burden of clinical activity they need to perform. Nevertheless, invited subjects may be likely to discuss the pros and cons of FIT screening with their PCPs. Thus, PCPs should be adequately informed about the FIT program and possibly informed when their patients receive the invitation. In our case, the differences are also the distance between place of residence and the endoscopy unit (also favoring PCPs invitation). However, overall expected costs would be significantly higher, and thus the option for both 'approaching' the endoscopic unit of the place of residence and also using the direct invitation.

The selection of a direct invitation strategy for our national program is not unexpected. All the European countries eventually came to adopt such an intervention that also simplifies the centralization of data and a timely use of limited resources. The fact that adherence in the pilot phase was only $30 \%$ should not discourage the healthcare system. Adherence to any screening intervention is known to grow over a mid- to long-term horizon, requiring the loyalty and trust of the general population regarding the screening program. In addition, it cannot be excluded that opportunistic screening mainly by primary colonoscopy is still competing with the organized approach in the short-term. However, the suboptimal adherence rate might bring the consideration of a more conservative approach. For instance, instead of wasting $70 \%$ of the FIT kits, other innovative means for promoting adherence to screening and colonoscopy will be considered in the future as full regional coverage for the program is reached and reasons behind non-adherence investigated.

Table 3 - Comparison with Zorzi M et al

\begin{tabular}{lcc}
\hline & Current report & Zorzi M et al \\
\hline Invitees (n) & 92573 & 178828 \\
Invitation method & Mailing & Mailing \\
Adherence to FIT (\%) & 29.0 & 69.0 \\
Positivity rate (\%) & 4.5 & 5.7 \\
Colonoscopies adherence (\%) & 60.0 & 91.5 \\
ADR (\%) & 41.0 & - \\
Advanced adenoma (\%) & 22.0 & 15.9 \\
Carcinoma (\%) & 2.0 & 3.34 \\
\hline
\end{tabular}


Our pilot implementation of a direct mailing invitation has shown the feasibility of a population-based program in Portugal. However, an unexpected suboptimal adherence to post-FIT colonoscopy was also disclosed. This is a critical problem as efficacy of a FIT program depends on the post-FIT+ removal of advanced neoplasia. Any loss of colonoscopy compliance directly translates into a loss of efficacy of FIT program in the first place. Possible alternatives can be explored. For instance, direct contact between the screening/endoscopic center and the patient may be proposed rather than to defer the positive patient to PCP as implemented in several European countries.

It is important also to highlight the high-quality parameters for the colonoscopies performed in all centers, namely the cecal intubation and bowel preparation, but more importantly, the adenoma detection rate were above standard. ${ }^{13}$ This is crucial to assess and to continuously monitor. These first results are very promising and allow us to think that those procedures performed within this context will guarantee long term results for the screening programme.

There are limitations to our study. We limited our analysis to the first round of FIT. It is well known that uptake of FIT is much higher at subsequent rounds in those who previously accepted. On the other hand, PPV for AN tends to decrease. We did not perform subgroup-analyses according to age and sex. It is known that female and older subjects tend to have a higher yield of uptake. We did not test different cut-off values of positivity for FIT. This is known to alter the detection rate as well as the PPV of colonoscopy. However, this is now secondary to the increase in uptake rate of FIT.

\section{CONCLUSION}

We showed the effectiveness of a centralized, direct FIT invitation in a Portuguese setting, resulting in a high feasibility of the program enabling PCPs to be allocated to other components of the programme (e.g., pre- and post-colonoscopy management). Further interventions are needed to increase uptake with FIT and compliance with post-FIT colonoscopy.

\section{AUTHORS CONTRIBUTIONS}

HM, FT, JR, MDR: Conception of the work, critical review and final approval of the version to be published.

GF: Conception of the work and final approval of the version to be published.

MJC, SC, LC, JC, IP, JS, RH, MJB, CH: Critical review and final approval of the version to be published.

\section{PROTECTION OF HUMANS AND ANIMALS}

The authors declare that the procedures were followed according to the regulations established by the Clinical Research and Ethics Committee and to the Helsinki Declaration of the World Medical Association updated in 2013.

\section{DATA CONFIDENTIALITY}

The authors declare having followed the protocols in use at their working center regarding patients' data publication.

\section{COMPETING INTERESTS}

The authors have declared that no competing interests exist.

\section{FUNDING SOURCES}

No financial support was received by any author.

\section{REFERENCES}

1. Bray F, Ferlay J, Soerjomataram I, Siegel R, Torre L, Jemal A. Global cancer statistics 2018: GLOBOCAN estimates of incidence and mortality worldwide for 36 cancers in 185 countries. CA Cancer J Clin. 2018;68:394-424.

2. Instituto Português de Oncologia do Porto. Registo Oncológico Regional do Norte, 2011. 2017 [accessed 2021 Jan 10]. Available from: http:// www.roreno.com.pt.

3. Institute for Health Metrics and Evaluation. Portugal. Institute For Health Metrics and Evaluation. 2017 [accessed 2021 Jan 10]. Available from: http://www.healthdata.org/portugal.

4. Organisation for Economic Co-operation and Development. Health at a Glance: Europe 2018. OECD; 2018 [accessed 2021 Jan 10]. Available from: https://www.oecd-ilibrary.org/social-issues-migration-health/ health-at-a-glance-europe-2018_health_glance_eur-2018-en.

5. Rex D, Boland C, Dominitz J, Giardiello F, Johnson D, Kaltenbach T, et al. Colorectal cancer screening: recommendations for physicians and patients from the U.S. Multi-Society Task Force on Colorectal Cancer. Am J Gastroenterol. 2017;112:1016-30.

6. Andermann A, Blancquaert I, Beauchamp S, Déry V. Revisiting Wilson and Jungner in the genomic age: a review of screening criteria over the past 40 years Public Health classics. Bull World Health Organ. 2008;86:317-9.

7. Zorzi M, Fedeli U, Schievano E, Bovo E, Guzzinati S, Baracco S, et al. Impact on colorectal cancer mortality of screening programmes based on the faecal immunochemical test. Gut. 2015;64:784-90.
8. European Colorectal Cancer Screening Guidelines Working Group, von Karsa L, Patnick J, Segnan N, Atkin W, Halloran S, et al. European guidelines for quality assurance in colorectal cancer screening and diagnosis: overview and introduction to the full supplement publication. Endoscopy. 2012;45:51-9.

9. Salas Trejo D, Portillo Villares I, Espinàs Piñol J, Ibáñez Cabanell J, Vanaclocha Espí M, Pérez Riquelme F, et al. Implementation of colorectal cancer screening in Spain. Eur J Cancer Prev. 2017;26:1726.

10. Areia M, Lorenzo F, Hassan C, Dekker E, Dias Pereira A, Dinis-Ribeiro M. Cost-utility analysis of colonoscopy or faecal immunochemical test for population-based organised colorectal cancer screening. United Eur Gastroenterol J. 2019;7:105-13.

11. Portugal. Despacho 4771-A/2016. Diário da Republica. $1^{\circ}$ Suplemento, II Série, n. ${ }^{\circ} 68$ (2016/04/07). p.11710-2.

12. Robertson D, Lee J, Boland C, Dominitz J, Giardiello F, Johnson D, et al. Recommendations on fecal immunochemical testing to screen for\&nbsp;colorectal neoplasia: a consensus statement by the US Multi-Society Task Force on colorectal cancer. Gastrointest Endosc. 2017;85:2-21.e3.

13. Kaminski M, Thomas-Gibson S, Bugajski M, Bretthauer M, Rees C, Dekker $E$, et al. Performance measures for lower gastrointestinal endoscopy: a European Society of Gastrointestinal Endoscopy (ESGE) Quality Improvement Initiative. Endoscopy. 2017;49:1-20. 